\title{
Journal of Nutraceuticals and Herbal Medicine
}

Journal Homepage: http://journals.ums.ac.id/index.php/jnhm

\section{Antioxidant Activity of Sunflower (Helianthus Annuus l.) Ethanolic Extract with DPPH Method and Determination of Total Phenolic and Flavonoid Levels}

\author{
Salwa, Muhtadi* \\ Faculty of Pharmacy, University of Muhammadiyah Surakarta, \\ Muhtadi@ums.ac.id
}

\begin{abstract}
Sunflower (Helianthus annuus L.) is believed to have antioxidant properties. Currently, there are many studies examining compounds that have benefits as antioxidants and are safe for health. However, the sunflower only examined the antioxidants in sunflower seeds. This study aims to determine the antioxidant activity of ethanol extract of flowers, bark, and leaves of sunflowers. The antioxidant activity test using the DPPH method showed the highest antioxidant activity was found in the leaf extract (Helianthus annuus L.) with an IC 50 value of $48.841 \mathrm{ppm}$. The highest phenolic content was found in leaf samples with a value of $35.149 \mathrm{mg}$ gallic acid equivalent/gram extract and the highest determination of flavonoid levels was found in leaf samples with a value of $10.917 \mathrm{mg}$ quercetin equivalent/gram extract.
\end{abstract}

Keywords: Helianthus annuus L., Antioxidant, DPPH, Phenolic, Flavonoid

\section{INTRODUCTION}

Antioxidants can stabilize or deactivate free radicals before they attack cells, so the risk of degenerative diseases such as cardiovascular, atherosclerosis, and other degenerative diseases can be reduced by consuming adequate amounts of antioxidants (Sayuti and Yenrina, 2015).

The sunflower plant has many benefits, one of which is as an antioxidant (Dwivedi, 2014). However, many studies have only examined the antioxidants in sunflower seeds. Several reports on research on sunflower plants, including methanol extract of sunflower seeds (Helianthus annuus L.) is known to contain phenolic compounds such as tannins, alkaloids, and flavonoid (Dwivedi, 2014). The ethanol extract of sunflower leaves has antioxidant, antidiarrheal, and antihistamine activity (Dwivedi and Sharma, 2015). The article written by Ali (2014) stated that the ethanolic extract of sunflower seeds had higher antioxidant activity, and (Juniarti \& Herdiana, 2003) explained that all parts of the sunflower plant have antioxidant, antitumor, and antimicrobial activities.

Phenol derivatives are secondary metabolites produced by plants. One of the largest groups of phenolic compounds is the flavonoid group. Phenolic compounds are natural compounds that have the ability as biologically active compounds, one of which is as an 
antioxidant which is considered capable of preventing and treating degenerative diseases (Alfian \& Susanti, 2012). Research conducted by Sahala, Aldo(2012)regarding the antioxidant activity test and determination of total phenolic content revealed that there is a correlation between the source of strong antioxidants and the content of total phenolic compounds. Phenol and flavonoid compounds contributed linearly to the activity, the higher the number, the better the antioxidant activity.

This paper is the result of research on the activity of the ethanol extract of sunflower (Helianthus annuus L.) extract using the DPPH method and measuring the total phenolic and flavonoid levels. The modification of the research to the previous study was Helianthus annuus L. which focused on the ethanol extract of the flowers, leaves, and stems of Helianthus annuus L. using the DPPH method along with the measurement of total phenolic and flavonoid levels.

\section{METHODS}

The extraction method used is maceration using 96\% ethanol. Determination of antioxidant activity using the DPPH method and the inhibitory concentration (IC ${ }_{50}$ ) value was calculated. Total phenolic content was measured spectrophotometrically using gallic acid as a comparison and total flavonoid levels were measured spectrophotometrically using quercetin as a comparison.

\section{Tools and Materials}

The tools used in this research are drying oven, analytical balance, maceration vessel, Buchner funnel, UV-Vis spectrophotometer (UV Mini SHIMADZU), cuvette, weighing bottle, measuring flask, volume pipette, measuring pipette, micropipette, macro pipette, blue tip, yellow tip, porcelain cup, glass beaker, horn spoon, stainless spoon.

The materials used consisted of flowers, leaves, the bark of sunflower plants (Helianthus annuus L.), 96\% ethanol (technical, Merck), absolute ethanol (pa, Merck) DPPH (pa, sigma), aquadest, aluminum foil, N2CO3 7.5\% (pa, Merck), Folin-Ciocalteu $10 \%$ (pa, Merck), gallic acid (pa, Merck) AlCl3 10\%, potassium acetate 1M, quercetin.

\section{Research Step}

\subsection{Sampling}

Sunflower plants were obtained from the Dukuh Jetis area, Simo, Boyolali district.

\subsection{Sample Extraction}

The research sample powder was macerated in $96 \%$ ethanol for $3 \times 24$ hours with a ratio of dry powder: ethanol $(1: 75)(\mathrm{g} / \mathrm{ml})$, with occasional stirring. The macerate was filtered using a Buchner vacuum, then evaporated using a rotary evaporator. The result was thickened with a water bath and the maceration was repeated 2 times.

\subsection{Preparation of Test Solution}

\subsubsection{Test Solution for Antioxidant Activity}

Weigh as much as $50 \mathrm{mg}$ of extract and dissolve with ethanol pa to $5 \mathrm{~mL}$. The solution was made into several concentrations, namely $60 ; 120 ; 140 \mu \mathrm{g} / \mathrm{ml}$.

\subsubsection{Test Solution for Determination of Total Phenolic Content}

The extract was weighed as much as $50 \mathrm{mg}$ and dissolved in ethanol pa to $10 \mathrm{~mL}$, the concentration of the test solution was $5,000 \mathrm{~g} / \mathrm{mL}$. 


\subsubsection{Test Solution for Determination of Total Flavonoid Level}

The extract solution was made by weighing $100 \mathrm{mg}$ of the extract and then dissolved with $10 \mathrm{~mL}$ of ethanol pa, a concentration of $1,000 \mathrm{~g} / \mathrm{mL}$.

\subsubsection{Preliminary Test}

\subsubsection{Preliminary Test of Antioxidant Activity}

A total of $1 \mathrm{~mL}$ of DDPH was added into three test tubes and $1 \mathrm{~mL}$ of the test solution was added to each tube, then $3 \mathrm{~mL}$ of ethanol pa was added to the mixture and left for 30 minutes, observing the color of the solution.

\subsubsection{Preliminary Test of Phenolic Compound}

$1 \mathrm{~mL}$ of the test solution and gallic acid comparison solution were put into three test tubes and $1.5 \mathrm{~mL}$ of Folin-Ciocalteu reagent was added. The mixture was allowed to stand for 6 minutes, added with $1.5 \mathrm{~mL}$ of $1 \mathrm{M}$ sodium carbonate solution and observed the color of the solution.

\subsubsection{Preliminary Test of Flavonoid Compound}

Qualitative testing of flavonoids with dilute $\mathrm{NaOH}$ reagent carried out by reacting the sample with dilute $\mathrm{NaOH}$ reagent. Judging from the yellow color formed indicates a positive sample containing flavonoids.

\subsubsection{Measurement of Antioxidant Activity}

\subsubsection{Preparation of DPPH Solution}

$10 \mathrm{mg}$ of DPPH was dissolved in ethanol pa to $100 \mathrm{ml}$, to obtain a DPPH solution with a concentration of $0.2 \mathrm{Mm}$. The solution should be covered with aluminum foil and always made fresh.

\subsubsection{Antioxidant Activity Testing DPPH Method}

$500 \mathrm{~L}$ of the test solution was taken from several different concentrations, then $1.0 \mathrm{~mL}$ of $0.2 \mathrm{Mm}$ DPPH was added, incubated for 45 minutes and then the absorbance was measured at a wavelength of $517.0 \mathrm{~nm}$. Then the results obtained were compared with a control solution consisting of $1.0 \mathrm{~mL}$ of DPPH and ethanol pa to $5.0 \mathrm{~mL}$. The experiment was repeated twice, \% antioxidant activity was calculated to make a linear regression curve between concentration and $\%$ antioxidant activity.

\subsubsection{Determination of total phenolic content}

\subsubsection{Preparation of Gallic Acid Standard Curve}

$10 \mathrm{mg}$ of gallic acid was dissolved in ethanol pa to a volume of $10 \mathrm{~mL}$. Pipette $2.5 \mathrm{~mL}$ of the stock solution then dilute with ethanol pa to $25 \mathrm{~mL}$ and obtain a concentration of $100 \mathrm{ppm}$. From the solution made several concentrations.

\subsubsection{Measurement of Total Phenolic Level}

The $50 \mathrm{mg}$ extract was dissolved in ethanol pa to a volume of $10 \mathrm{~mL}$. Pipette $1 \mathrm{~mL}$ of the extract solution obtained and add $1.5 \mathrm{~mL}$ of Folin-Ciocalteu reagent and shake. let stand for 3 minutes, add $1.2 \mathrm{~mL}$ of $7.5 \% \mathrm{Na} 2 \mathrm{CO} 3$ solution and leave at room temperature for 45 , measure the absorbance of the solution at the maximum wavelength and repeat 3 times(Lim \& Murtijaya, 2007).

\subsubsection{Determination of total flavonoid levels}

\subsubsection{Preparation of Quarcetine Standard Curve}


Weigh $10 \mathrm{mg}$ of standard quercetin and dissolve in ethanol pa at a concentration of $1000 \mathrm{ppm} .1 \mathrm{~mL}$ of the standard solution was pipetted and dissolved in $10 \mathrm{~mL}$ of ethanol pa with a concentration of $100 \mathrm{ppm}$, then made several concentrations. $3 \mathrm{~mL}$ of ethanol pa was added and $0.2 \mathrm{~mL}$ of $10 \% \mathrm{AlCl} 3$ into a standard solution of quercetin of each concentration and allowed to stand for 6 minutes. After that, add $0.2 \mathrm{~mL}$ of $1 \mathrm{M}$ potassium acetate and dilute the distilled water to $10 \mathrm{~mL}$. Then incubated at room temperature for 30 minutes.

\subsubsection{Measurement of Total Flavonoid Level}

Some modifications are based on the colorimetric determination of total flavonoids in the reference procedure(Chang, Chia-chi., et al and Chern, 2002) and (Ahmad \& Asrifa, 2014) using quercetin (QE) as a standard, then weighed $100 \mathrm{mg}$ of the extract dissolved in $10 \mathrm{~mL}$ of ethanol pa, $2.5 \mathrm{~mL}$ of flower part solution, $150 \mathrm{~L}$ leaf part solution and $5.5 \mathrm{~mL}$ stem bark solution were taken. Add $3 \mathrm{~mL}$ of ethanol and $0.2 \mathrm{~mL}$ of $10 \% \mathrm{AlCl} 3$ then let stand for 6 minutes. After the solution was allowed to stand, $0.2 \mathrm{~mL}$ of $1 \mathrm{M}$ potassium acetate was added and made up with distilled water to $10 \mathrm{~mL}$. Then it was incubated at room temperature for 30 minutes and the absorbance was measured at a wavelength of $441 \mathrm{~nm}$.

\section{RESULTS AND DISCUSSION}

Basically, extraction is the process of taking chemical compounds using certain solvents contained in the sample. The purpose of this process is to take the chemical compounds contained in the sample, the principle is based on the mass transfer of the solute component to the solvent, so that the transfer occurs at the interface layer and diffuses into the solvent. In this study, sample extraction by maceration process will be carried out for $3 \times 24$ hours. The contact that occurs between the powder and the solvent solution during the immersion process causes the simplicia addictive substance to dissolve in the solvent (Kurniati, et al 2007) to carry out the extraction used 96\% technical ethanol solvent as a polar solvent. In terms of filtration, ethanol solvent is used because it has advantages compared to methanol and water. Hanani et al. (2005) mention in their article that flavonoid compounds will form glycosides, causing the compound to easily dissolve in polar solvents. While ethanol is a solvent that can penetrate the wall to facilitate the extraction of secondary metabolites (Tiwari and Kaus, 2017). Then the extract obtained from the experimental results was concentrated with a rotary evaporator to produce a concentrated extract.

Table 1. The yield of flower, leaf, and stem extracts Helianthus annuus $L$.

\begin{tabular}{cccc}
\hline Sample & $\begin{array}{c}\text { Extract Weight } \\
\text { (grams) }\end{array}$ & $\begin{array}{c}\text { Simplicia Weight } \\
\text { (grams) }\end{array}$ & $\begin{array}{c}\text { yield } \\
\text { (\%) }\end{array}$ \\
\hline Leaf & 10.25 & 289.71 & 3.52 \\
\hline Bark & 9.21 & 198 & 4.65 \\
\hline Flower & 8.85 & 32.47 & 27.25 \\
\hline
\end{tabular}

After maceration is done, the extract yield of each part is calculated with the calculations contained in Appendix 1. The yield value is obtained from the calculation results in the form of a percent. The ethanolic extract of flowers has the highest yield value of $27.25 \%$, while the ethanolic extract of the stem bark is $4.65 \%$ and the lowest is leaf ethanol extract with a yield of $3.52 \%$. The highest yield of flower extract shows that 
this extraction process is efficient in extracting flowers (Dewatisari et al., 2018) While the extraction process is less efficient in extracting the leaves of Helianthus annuus L.

\section{Preliminary Test of Antioxidant Compounds}

Testing on sunflower plants was carried out to show the presence of compounds with antioxidant activity in sunflower extracts which were carried out qualitatively. During the test, there was a reaction between DPPH radicals and antioxidant compounds. The color of the DPPH solution turns yellow due to the influence of antioxidant compounds. To show a positive control, the DPPH solution was added with vitamin E which is known to have very strong antioxidant activity with an IC50 value of $21.76 \mathrm{ppm}$. (Lung, et al., 2018), Meanwhile, to show negative control, DPPH solution was used. The test step is carried out by adding DPPH to the test solution and a comparison compound (vitamin E) and then observing the color changes that occur. For a positive result, the test solution is yellow (Figure 1). This is due to the potential of ethanol extract in sunflower plants as antioxidants (Irwanta, 2014).
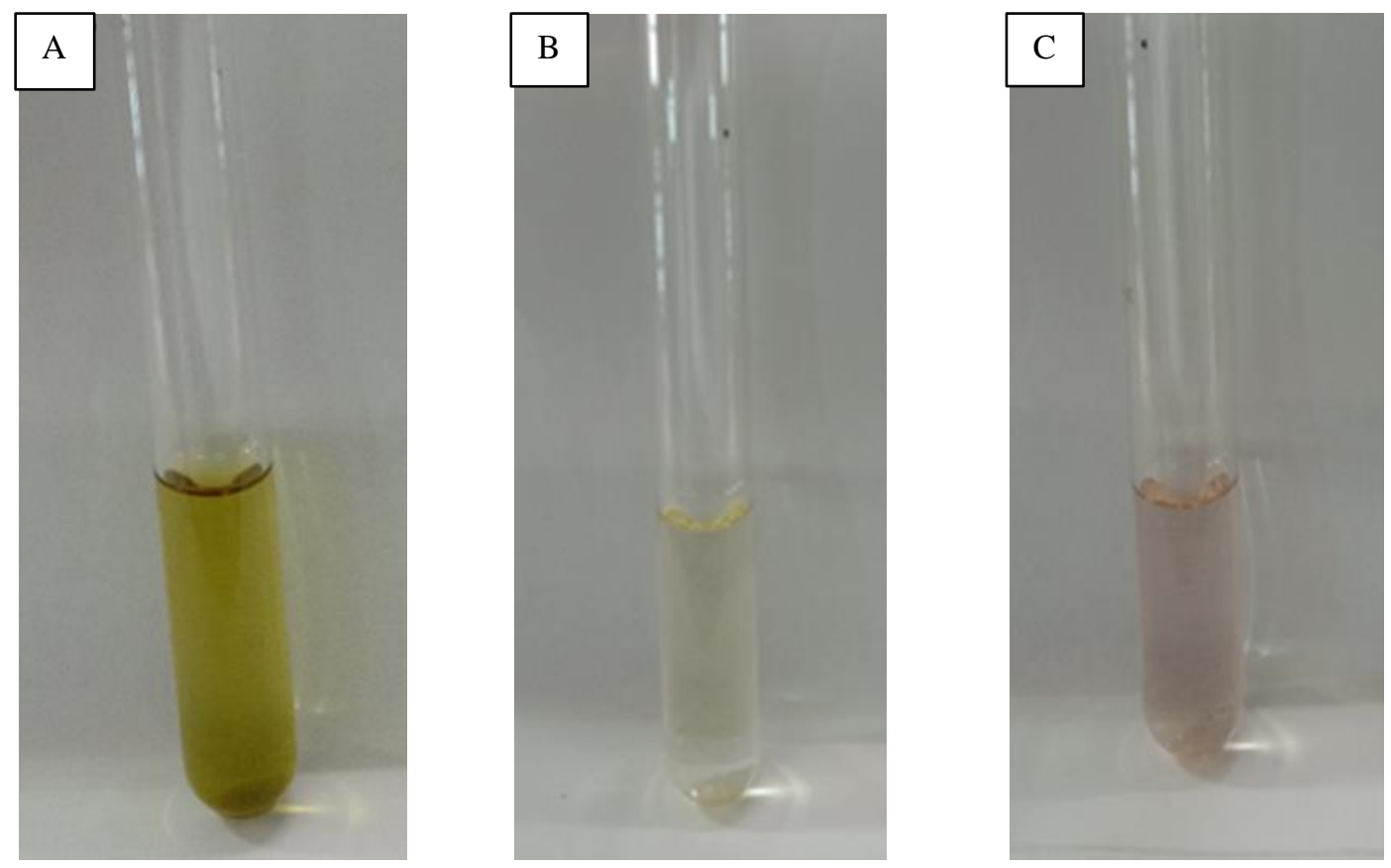

Figure 1. $A=$ Leaf extract $+D P P H ; B=$ Flower extract $+D P P H ; C=$ Bark Extract $+D P P H$

\section{Preliminary Test of Phenolic Compound}

To determine the presence of phenolic compounds in the ethanolic extract of sunflower plants, a qualitative test was carried out. The test was carried out by adding Folin-Ciocalteu reagent and sodium carbonate solution in the test solution. The color change of the test solution to blue is due to the presence of phenolic compounds. Usually, the change occurs when phosphomolybdic-phosphotungstic acid is reduced in the FolinCiocalteu reagent by a polyphenol compound to form molybdenum blue, forming a blue complex. The darker the blue color produced, the higher the percentage of phenol in the sample. The positive control used in this test was the Folin-Ciocalteu reagent added with gallic acid and the negative control used was Folin-Ciocalteu. The phenolic compound used as a comparison is gallic acid(Irwanta, 2014). 
In this test, positive results were obtained with the formation of a blue color (figure 2) which indicates that the ethanolic extract of sunflower plants contains phenolic compounds.
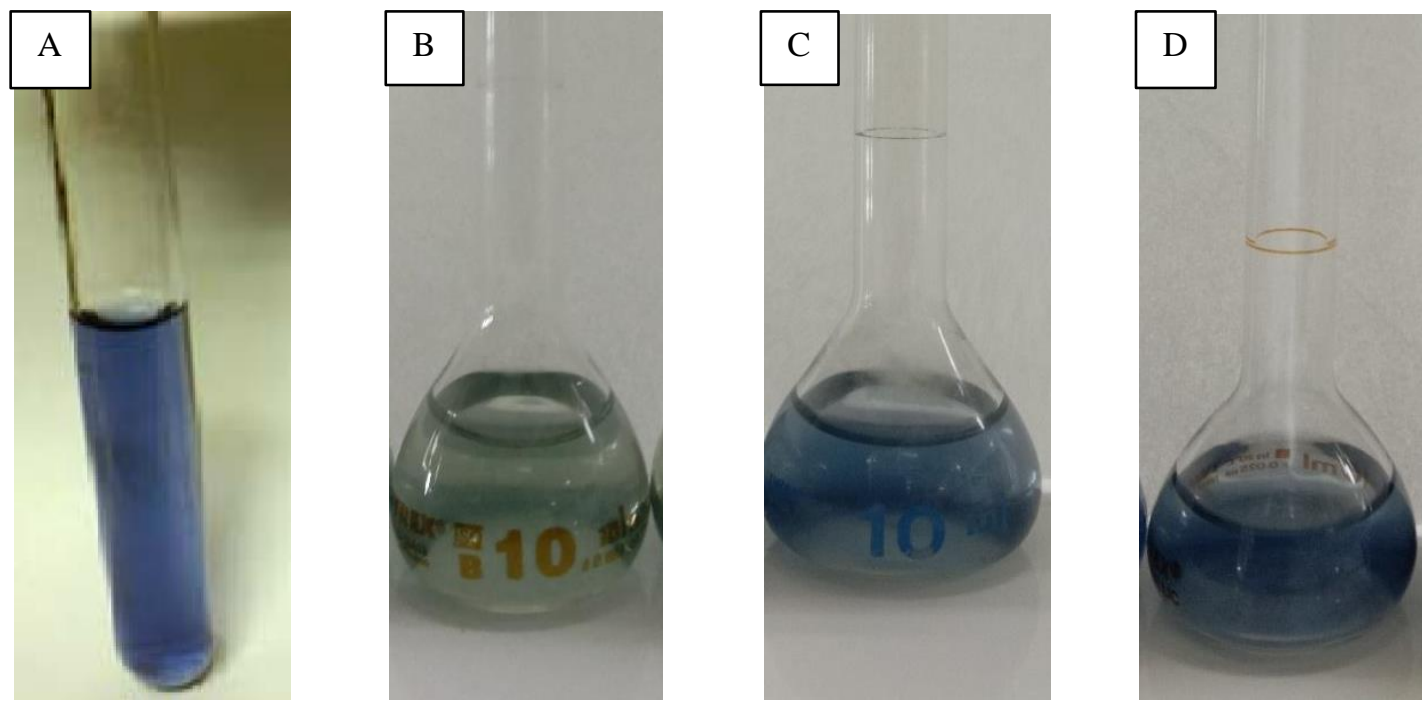

Figure 2. $(A=$ Positive control [gallic acid + Folin Ciocalteu]; $B=$ Leaf sample + Folin Ciocalteu + Gallic acid; C = Bark sample + Folin Ciocalteu + Gallic acid; D = Flower sample + Folin Ciocalteu + Gallic acid.)

\subsection{Preliminary Test of Flavonoid Compound}

The qualitative test was carried out by adding a few drops of dilute $\mathrm{NaOH}$ to the sample solution, if the sample contained flavonoids, the color changed to yellow. The yellow color is caused by derivatives of flavone/flavonol compounds which will be degraded into molecules such as acetophenone which are yellow due to the breaking of bonds in the isoprene structure (Lindawati \& Ma'ruf, 2020).
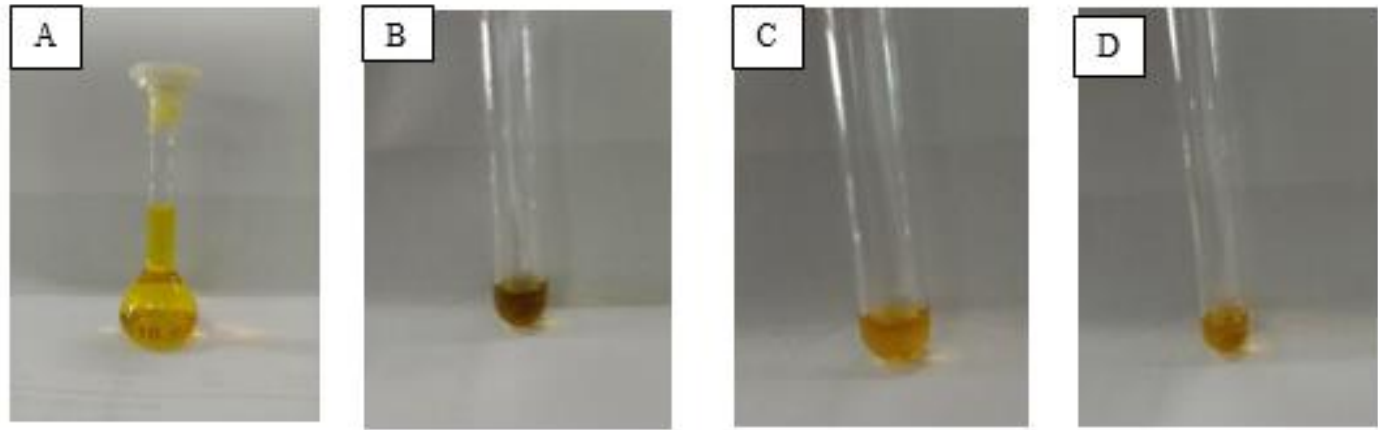

Figure 3. $(\mathrm{A}=$ positive control [quercetin $+\mathrm{NaOH}] ; \mathrm{B}=$ Leaf sample $+\mathrm{NaOH} ; \mathrm{C}=$ bark sample $+\mathrm{NaOH} ; \mathrm{D}=$ Flower sample $+\mathrm{NaOH}$

\section{Antioxidant Activity Test with DPPH . Method}

Antioxidant activity was tested quantitatively by the DPPH method (2, 2-diphenyl-1picrylhydrazyl). This method was chosen because it is simple, fast, and easy, and the sample required is not too large. The principle of measurement of the DPPH method is the change in color intensity. The color change is caused by the reduction of free radicals generated by the reaction with DPPH and hydrogen atoms released from the sample compound and causes a color change in DPPH from purple to yellow. The stronger antioxidant compound in the test sample can cause the DPPH color to fade. According to 
Molyneux (2004) this color change affects the change in absorbance of the maximum wavelength of DPPH when measured using UV-Vis spectrophotometry so that the known free absorbing activity is expressed by the IC 50 value. linear regression. The data obtained are as shown in table 2 (more details are listed in the attachment).

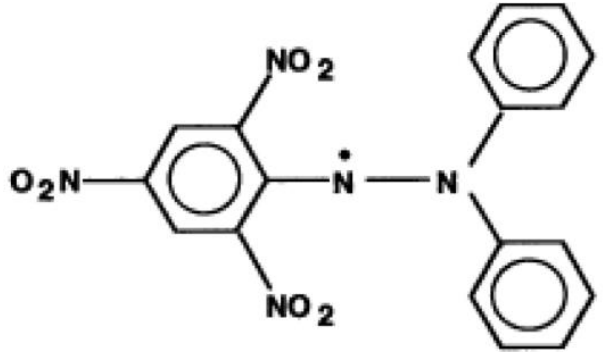

(a)

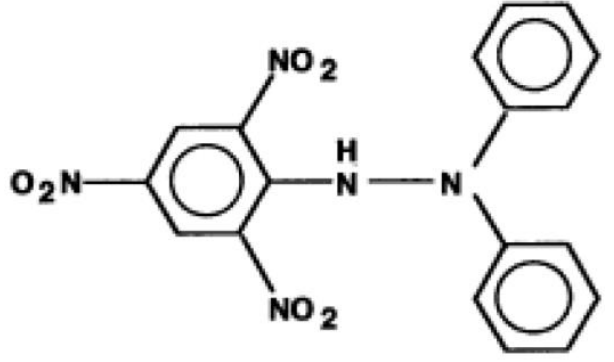

(b)

Figure 4. Diphenylpicrylhydrazyl form of free radicals (a), Diphenyloicrylhydrazyl from reaction with extract (b)

Table 2. Results of Measurement of Antioxidant Activity of the DPPH . Method

\begin{tabular}{cc}
\hline Sample & IC50 (ppm) \\
\hline Leaf & 48.841 \\
\hline Bark & 274,026 \\
\hline Flower & 180,504 \\
\hline Vitamin E & 27.97
\end{tabular}

According to (Endrini, Susi., 2009) A compound will be more effective as a free radical scavenger if the IC50 value is getting smaller. Table 2 above shows that the samples that have the strongest antioxidant activity or the smallest IC50 value are leaf extract (48.841 ppm), flower extract (180.504 ppm) have a weak antioxidant intensity and ethanol extract of stem bark has the highest IC50 or the antioxidant intensity is not. active (274.026 ppm).

Specifically, a compound is said to be a very strong antioxidant if the IC50 value is $<50$ ppm, strong for IC50 is $50-100$ ppm, moderate if IC50 is $100-150 \mathrm{ppm}$, and weak if IC50 is $151-200 \mathrm{ppm}$ (Mardawati, 2008).

In the positive control test, vitamin E in the DPPH method was used as a comparison. The IC50 value resulting from the positive control test was $27.97 \mathrm{ppm}$ so it was included in the category of very strong antioxidant intensity $(<50 \mathrm{ppm})$.

\section{Determination of Total Phenolic Level}

This research was conducted to determine the total phenolic content in flower, leaf, and stem bark extracts of sunflower (Helianthus annuus L.) with gallic acid (GAE) as a comparison solution. Gallic acid is a natural phenolic compound derived from hydroxybenzoic acid. This gallic acid reacts with Folin-Ciocalteu in alkaline conditions to produce a yellow color which is a positive sign or contains phenol. Phenolic compounds react under alkaline conditions to separate protons into phenolic ions. Therefore, the base solution that is included for the determination of the total phenolic compound content is the Na2CO3 solution which gives a blue color(Alfian \& Susanti, 2012).

Table 3. Results of Determination of Total Phenolic Levels

Sample Average Total Phenolic Content




\begin{tabular}{cc}
\hline & (mg gallic acid equivalent/g extract) \\
\hline Leaf & $35.149 \pm 10.146$ \\
\hline Bark & $17,462 \pm 6.035$ \\
\hline Flower & $24,884 \pm 3,350$ \\
\hline
\end{tabular}

The table above shows the phenolic content of each sample. Leaf extracts in sunflower plants had phenolic levels of 35.149 mg gallic acid equivalent/g extract which was higher than the bark extract with a value of 17.462 this was caused by sampling during the day when the intensity of the sun was high. Through research(Ibrahim \& Jaafar, 2012) said that the relationship between the level of solar radiation and the content of phenolics and flavonoids is that the higher the exposure to solar radiation, the lower the production of phenolics and flavonoids.

\section{Determination of Total Flavonoid Level}

To determine the total flavonoid content in the ethanol extract of sunflower (Helianthus annuus. L) plants, a quantitative analysis of total flavonoid compounds was carried out using UV-Vis spectrophotometry. The analysis of flavonoids was carried out by UV-Vis spectrophotometry because flavonoids contain a conjugated aromatic system so that they show strong absorption bands in the ultraviolet and visible light spectrum regions.(Aminah \& Abidin, 2017). In this study, to determine the total flavonoid content in the sample, quercetin was used as a standard solution with a concentration series of $49.0 ; 57.5 ; 62.5 ; 100 ; 180.0 \mathrm{ppm}$, the concentration series is used to determine the standard curve. To create a standard curve, several concentration series are first made to obtain a linear equation that can be used to calculate the percent concentration. The choice of concentration is based on Lambert-Beer's law, which states that the absorption conditions are $0.2-0.8$. This is to avoid photometric errors so that the analytical error is still within the acceptable range of 0.5-1\% (Wahdaningsih, 2017). Measurement of the maximum wavelength absorption is carried out running from a wavelength of 400-450 $\mathrm{nm}$. The results of running show that the maximum wavelength of the quercetin standard is at a wavelength of $441 \mathrm{~nm}$. This maximum wavelength was used to measure the uptake of ethanol extract samples in sunflower plants (Helianthus annuus. L).

In the measurement of total flavonoid levels, the addition of $\mathrm{AlCl} 3$ and Potassium Acetate. Sample solution that has reacted with $\mathrm{AlCl} 3$ and potassium acetate left in the dark because the complex formed is sensitive to light. AlCl3 solution is used to form colored complexes with flavonoids, thus shifting the wavelength to visible light and the solution produces a more yellow color. Add solution potassium Acetate (CH3CO2K)to stabilize and maintain wavelengths in the visible light region. The principle of using $\mathrm{AlCl} 3$ to analyze total flavonoids is that $\mathrm{AlCl} 3$ forms a complex with a ketone group on the $\mathrm{C}-4$ atom and a hydroxyl group on the adjacent C-3 or C-5 atom of flavonoids and flavonols.

Table 4. Results of Determination of Flavonoid Levels

\begin{tabular}{cc}
\hline Sample & $\begin{array}{c}\text { Average Flavonoid Level } \\
\text { (mg quarcetine equivalent/g extract) }\end{array}$ \\
\hline Leaf & $10.917 \pm 1.327$ \\
\hline Bark & $2.598 \pm 0.461$ \\
\hline Flower & $4.576 \pm 0.268$ \\
\hline
\end{tabular}


The table above shows that the sunflower plant which has the highest flavonoid content is the leaf extract portion of $10.917 \mathrm{mg}$ equivalent to quercetin/g extract, which means that in 1 gram of ethanolic leaf extract the equivalent of $10.917 \mathrm{mg}$ of quercetin while the bark extract part has a flavonoid content of $2.598 \mathrm{mg}$. quercetin equivalent/g extract. The higher the flavonoid content, the higher the antioxidant potential. In this study, the flavonoid levels in sunflower leaf extract were higher than in sunflower bark extract because the leaves are the site of plant photosynthesis. Phenolic compounds are found in plant cells that undergo photosynthesis (Lukman, et al., 2016).

\section{Correlation of antioxidant activity with phenolic and flavonoid}

According to Pertiwi (2018), phenolic compounds have antioxidant activity through electron transfer, because phenolic compounds can prevent oxidation so that the higher the phenolic content, the higher the antioxidant activity (Djapiala, et al., 2013). Linear regression was calculated to determine whether there was a correlation between phenolic levels as the (X) axis and antioxidant activity (DPPH) as the (Y) axis as shown in Figure 5. From the results of the regression equation, $Y=-0.0785 x+39.004$ with $R^{2}=1$. Meanwhile, flavonoid compounds are also suspected to have a relationship with the antioxidant activity of an extract. So linear regression was calculated to see whether flavonoid levels as the (X) axis correlated with antioxidant activity as the (Y) axis as shown in Figure 6. The linear regression equation was obtained, namely $\mathrm{Y}=-0.0377 \mathrm{x}+$ 12,352 with R2 $=0.962$. Each method has a coefficient of determination (R2 $=1$ or equal to $100 \%$ ). It can be concluded that the levels of phenolic and flavonoid in extract $100 \%$ affect the antioxidant activity of the DPPH method. If the total phenolic and flavonoid levels are high, the antioxidants are also high, because total phenolic and total flavonoids are contributors to antioxidant activity in the DPPH method (Das et. al., 2014).

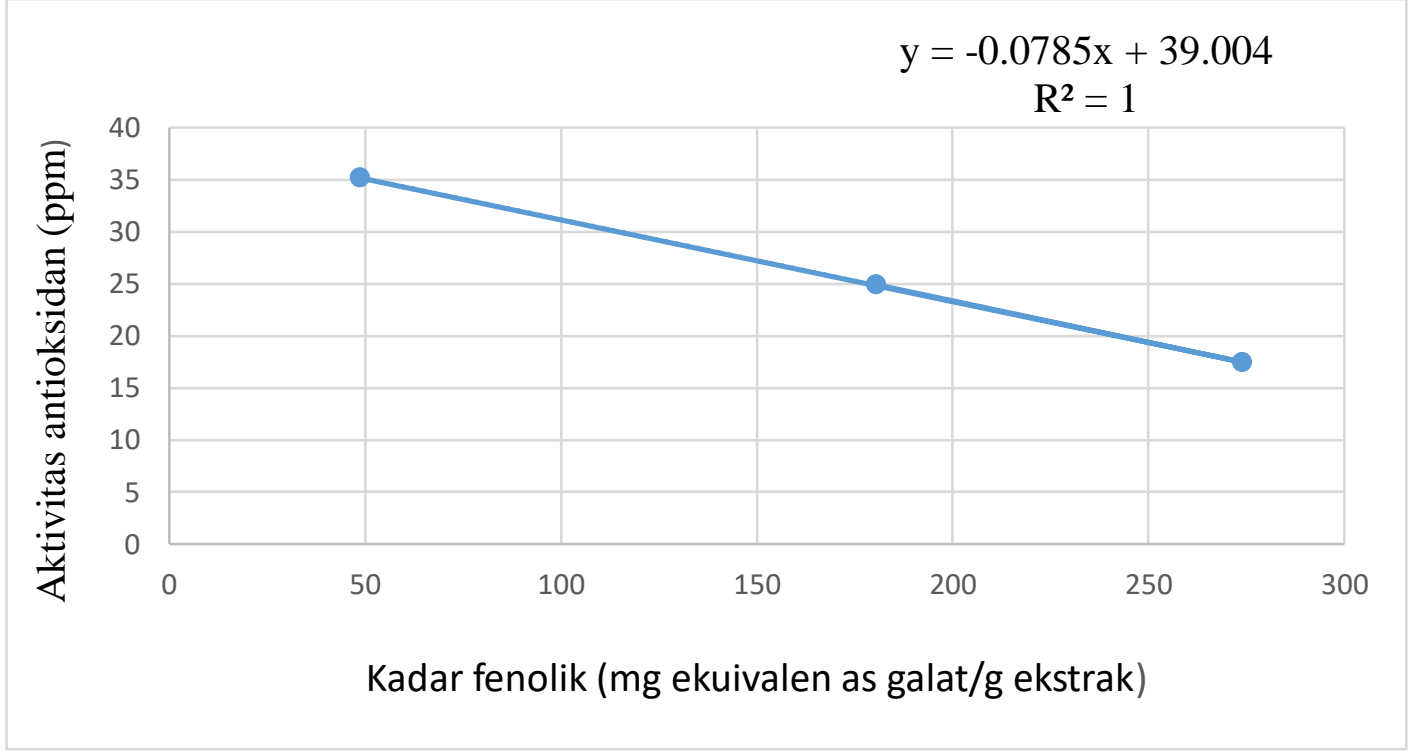

Figure 5. The relationship between phenolic levels and antioxidant activity using the DPPH method. 


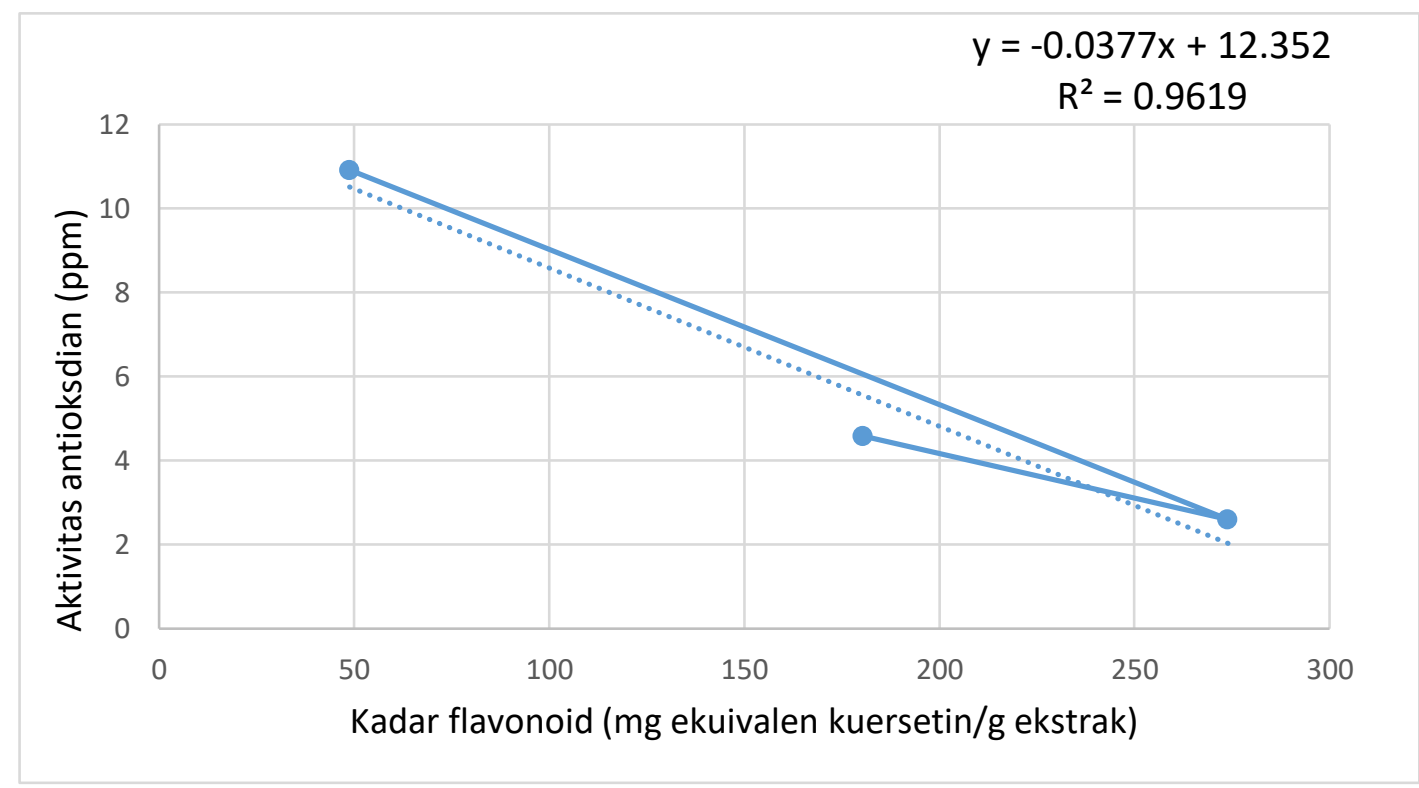

Figure 6. Relationship between flavonoid levels and antioxidant activity using the DPPH method.

\section{CONCLUSIONS}

Based on the results of the research conducted, the DPPH method of leaf extract $(48.841 \mathrm{ppm})$ has the strongest antioxidant activity. While the flower extract $(180.504$ $\mathrm{ppm}$ ) has a weak antioxidant intensity and the ethanol extract of the bark has the highest IC50 or the antioxidant intensity is not active $(274.026 \mathrm{ppm})$. The highest total phenolic content was found in the leaves of $34,149 \mathrm{mg}$ gallic acid equivalent/g extract and the highest flavonoid levels were found in the extract of sunflower plant leaf samples with $10.917 \mathrm{mg}$ quercetin equivalent/g extract. Antioxidant activity has a very strong or very high correlation with phenolic compounds and total flavonoids.

\section{REFERENCES}

Ahmad, AR, \& Asrifa, WO (2014). Study of Antioxidant activity and determination of Phenol and Flavonoid content of Pepino's Leaf extract (Solanum muricatum Aiton). In the International Journal of PharmTech Research.

Alfian, R., \& Susanti, H. (2012). Determination of Total Phenolic Content of Methanol Extract of Red Rosella Flower Petals (Hibiscus Sabdariffa Linn) With Spectrophotometric Variations in Growing Places. Pharmaciana, 2(1).

Ali, GM (2014). Evaluation of Antioxidant Activity of Ethanolic Extract from Irradiated Sunflower (Helianthus Annuus L.) Seeds Hull. Journal of Natural Sciences Research, Vol 4(1), 2225-2921.

Aminah, A., \& Abidin, Z. (2017). Determination of Total Flavonoid Content of Avocado Peel (Persen Americana Mill.) Ethanol Extract with UV-Vis Spectrophotometric Method. Journal of Indonesian Fitofarmaka, 4(2), 226-230.

Chang, C., Yang, M.H., Wen, H.M., and Chern, J. (2002). Estimation of Total Flavonoid 
Content in Propolis by Two Complementary Colorimetric Methods. Journal of Food and Drug Analysis, Vol 10(No 3), 178-182.

Das, N., Islam, MD., Jahan, N., Islam, MS., Khan, A., Islam, MR., and Parvin, MS (2014). Antioxidant activities of ethanol extracts and fractions of Crescentia cujete leaves and stem bark and the involvement of phenolic compounds. BMC Complementary and Alternative Medicine, Vol 14.

Dewatisari, WF, Rumiyanti, L., \& Rakhmawati, I. (2018). Yield and Phytochemical Screening on Leaf Extract of Sanseviera sp. Yield and Phytochemical Screening using Leaf extract of Sansevieria Sp . Journal of Applied Agricultural Research, 17(3), 197202.

Djapiala, Fera Yusniarti., et al and Menntang, F. (2013). Total phenol content in seaweed (Caulerpa racemosa) which has potential as an antioxidant. Fishery Product Technology Media.

Dwivedi, A., and Sharma GN, KA (2015). Research Articles. School of Pharmaceutical Sciences, Jaipur National University, Jaipur, Rajasthan, India Received., 6(1), 118124.

Dwivedi A., SG (2014). A Review on Heliotropism Plant : Helianthus annuus L . 3(2), 149155.

Endrini, Susi., et al. (2009). Antioxidant activity and cytotoxic effect of Kola extract (Cola nitida) on liver cancer cell culture (HepG-2) Antioxidant activities and cytotoxic effect of Cola nut. Yarsi Journal of Medicine, 17(1), 40-44.

Hanani, E., Munim, A., \& Sekarini, R. (2005). Identification of Antioxidant Compounds in Callyspongia Sp Sponges from the Thousand Islands. Pharmaceutical Science Magazine, 2(3), 127-133.

Ibrahim, MH, \& Jaafar, HZE (2012). Primary, secondary metabolites, H 20 2, malondialdehyde and photosynthetic responses of Orthosiphon stimaneus benth. to different irradiance levels. Molecules, 17(2), 1159-1176.

Irwanta, D. (2014). Determination of total phenolic content and antioxidant activity test using dpph method, thesis. Scientific Journal, 4(1), 23-28.

Juniarti, R., \& Herdiana, Y. (2003). Review Article : Extract Activity of Helianthus Annuus L. Farmaka, Vol. 15 Nos, 195-199.

Kurniati, Dian., and indarningsih, F. (2007). Study of the Effect of Heating on Antioxidant Activity of Noni (Morinda Citrifolia) as an Alternative Functional Food Source. 3(1), 20-25.

Lim, YY, \& Murtijaya, J. (2007). Antioxidant properties of Phyllanthus amarus extracts as affected by different drying methods. LWT - Food Science and Technology, 40(9), 1664-1669.

Lindawati, NY, \& Ma'ruf, SH (2020). Determination of Total Flavonoid Content of Red 
Bean (Phaseolus Vulgaris L.) Ethanol Extract with Visible Spectrophotometric Colorimetric Complex Method. Manuntung Scientific Journal, 6(1), 83.

Lukman, Hilmia., et al and Retnaningtyas, Y. (2016). Determination of Flavonoid Levels in Plant Leaf Extracts Using NIR and Chemometric Methods. Health Library E-Journal, 4, 8-13.

Lung, JKS and Destiani, D. (2018). Antioxidant Activity Test of Vitamins A, C, E with DPPH Method. Farmaka, 15(1), 53-62.

Molyneux, P. (2004). The use of the stable free radical diphenylpicryl-hydrazyl ( DPPH ) for estimating antioxidant activity. Songklanakarin Journal of Science and Technology, vol 50.

Sahala, Aldo and C, J, S. (2012). Antioxidant activity test and determination of total phenolic content of water fraction of ketapang leaves (Pharmacy and Community Science, 9(2), 91-97.

Sayuti, K., and Yenrina, R. (2015). Natural and Synthetic Antioxidants. Andalas University Press. Matter. 10-14.

Tiwari, P., et al and Kaur, H. (2017). Phytochemical Screening and Extraction : A Review. Hepatology, 66(6), 1866-1884.

Wahdaningsih, S., et al. (2017). Determination of Total Phenolic and Total Flavonoid Levels of Methanol Extract and Ethyl Acetate Fraction of Red Dragon Fruit Skin (Hylocereus Polyrhizus (FaCWeber) Britton and Rose). Pharmacon, 6(3), 295-301. 